\title{
Etiopathogenesis of Erythema Multiforme - A Concise Review
}

\author{
Rakhi Issrani ${ }^{1 *}$ and Namdeo Prabhu ${ }^{2}$ \\ ${ }^{1}$ Department of Preventive Dentistry, Al Jouf University, Saudi Arabia \\ ${ }^{2}$ Department of Oral and Maxillofacial Surgery, Al Jouf University, Saudi Arabia
}

Submission: March 16, 2017; Published: September 06, 2017

*Corresponding author: Rakhi Issrani, Lecturer, Department of Preventive Dentistry, College of Dentistry, Al Jouf University, Sakakah, Kingdom of Saudi Arabia, Email: dr.rakhi.issrani00@gmail.com

Abstract

Erythema multiforme is a reactive muco-cutaneous disorder in a disease spectrum that comprises a self-limited, mild, exanthematic cutaneous variant with minimal oral involvement (minor form) to a progressive, fulminating, severe variant with extensive muco-cutaneous epithelial necrosis (major form). These prototypes are well defined, but their distinction may be difficult in practice because of their overlapping features. Hence this literature review describes the associated potential etiologic agents and pathogenic mechanisms of erythema multiforme that may aid in early and accurate diagnosis of this lesion to prevent the complications and morbidity associated with this entity.

Keywords: Autoimmune; Erythema multiforme; Herpes; Hypersensitivity; Stevens-Johnson syndrome

\section{Introduction}

Erythema multiforme (EM) is a clinical conundrum, the name of which reflects the broad morphological spectrum of the lesions [1]. It is an acute, self-limited, episodic and muco-cutaneous inflammatory disorder of the skin and mucous membranes that could be related to immunologic [2] hypersensitivity reaction to certain infections, medications, and other various triggers [3]. It is classified into the following variants- [3]

i. $\quad$ Erythema multiforme minor (EM minor) - Typical targets or raised, edematous papules distributed acrally.

ii. Erythema multiforme major (EM major) - Typical targets or raised, edematous papules distributed acrally with involvement of one or more mucous membranes; epidermal detachment involves less than $10 \%$ of total body surface area (TBSA).

iii. Stevens-Johnson syndrome (SJS) - detachment below $10 \%$ of the TBSA plus widespread erythematous or purpuric macules or flat atypical targets and

iv. Toxic epidermal necrolysis (TEN) - detachment above $30 \%$ of the body surface area plus widespread purpuric macules or flat atypical targets.
Other miscellaneous variants of EM are recurrent EM where EM occurs over multiple years [3] and a rare variant of EM referred to as persistent EM, which is characterized by a continuous, uninterrupted state of both typical and atypical lesions with widespread involvement of skin and mucous membrane [4].

These prototypes are well defined, but their distinction may be difficult in practice because of their overlapping features. Hence the present article reviews the associated potential etiologic agents and pathogenic mechanisms of EM that may aid in early and accurate diagnosis of EM to prevent the complications and morbidity associated with this entity.

\section{Etiology and risk factors}

The etiology of EM is still unclear to this day [5]. Although hundreds of factors have been reported to cause EM, only a limited number are reasonably well documented as possible precipitating agents.6 It is considered as side effect reaction against certain microorganisms, radiotherapy, systemic diseases, malignancy, and food or drug allergy [5]. The potential etiologic agents associated with EM are mentioned in (Table 1) [6] and the commonest stimuli are briefly described as follows- 
Table 1: Conditions associated with erythema multiforme [3].

\begin{tabular}{|c|c|}
\hline Cause & Details \\
\hline \multicolumn{2}{|l|}{ 1. Infections } \\
\hline a. Viral & $\begin{array}{l}\text { HSV, Adenovirus, coxsackie virus B5, cytomegalovirus (CMV), echoviruses, } \\
\text { enterovirus, Epstein-Barr virus (EBV), hepatitis A/B/C viruses, influenza, } \\
\text { measles, mumps, paravaccinia, parvovirus B19, poliomyelitis, varicella- } \\
\text { zoster virus, and variola. Virus-drug interactions include CMV infection- } \\
\text { terbinafine and EBV infection-amoxicillin. }\end{array}$ \\
\hline b. Bacterial & $\begin{array}{l}\text { Mycoplasma pneumonia, borreliosis, catscratch disease, diphtheria, } \\
\text { hemolytic streptococci, legionellosis, leprosy, Neisseria meningitidis, } \\
\text { Mycobacterium avium complex, pneumococci, tuberculosis, proteus, } \\
\text { pseudomonas, salmonella, staphylococcus, yersinia species, treponema } \\
\text { pallidum, tularaemia, vibro parahaemolyticus, and rickettsial infections. } \\
\text { Chlamydial infections include lymphogranuloma venereum and } \\
\text { psittacosis. }\end{array}$ \\
\hline c. Fungal & Coccidioidomycosis, dermatophytosis, and histoplasmosis. \\
\hline d. Parasitic & Trichomonas species and Toxoplasma gondii. \\
\hline 2. Drug reactions & Antibiotics, anticonvulsants, antineoplastic agents, etc. \\
\hline \multirow{9}{*}{ 3. Others } & $\begin{array}{l}\text { - Diseases like collagen diseases, vasculitides, non-Hodgkin lymphoma, } \\
\text { leukaemia, multiple myeloma, myeloid metaplasia, and polycythemia. }\end{array}$ \\
\hline & $\begin{array}{l}\text { - Physical or mechanical factors - Radiotherapy, cold, sunlight, and } \\
\text { tattooing. }\end{array}$ \\
\hline & - Flavourings and preservatives like benzoic acid and cinnamon. \\
\hline & $\begin{array}{l}\text { - Contact exposure to ammoniated mercury, budesonide, } \\
\text { bufexamac, capsicum, chloromethylnaphthalene, desoximetasone, } \\
\text { dinitrochlorobenzen, disperse blue 124, diphenylcyclopropenone, fire } \\
\text { sponge (Tedania ignis), herbal medicines (eg, Alpinia galanga), isopropyl- } \\
\text { p-phenylenediamine of rubber, nickel, nitrogen mustard, oxybenzone, } \\
\text { phenylbutazone, poison ivy, proflavin, resin, rosewood, and triamcinolone } \\
\text { acetonide. }\end{array}$ \\
\hline & $\begin{array}{l}\text { - Postvaccination like Bacille Calmette-Guerin (BCG) vaccination, oral polio } \\
\text { vaccine, vaccinia, and tetanus/diphtheria. }\end{array}$ \\
\hline & - Foods like salmon berries and margarine. \\
\hline & - Malignancy. \\
\hline & - Pregnancy. \\
\hline & - Insect bite. \\
\hline
\end{tabular}

\section{Infections}

Infections are the most common cause of EM with herpes simplex virus being the most frequent precipitator [7]. Among the other infections, Mycoplasma infection appears to be a common cause [3].

\section{Herpes simplex}

Herpes simplex virus (HSV) (types 1 \& 2) is a vastly underappreciated cause of EM, with $15 \%$ to $63 \%$ of cases associated with this virus $[6,8,9]$. HSV is the most common cause in young adults; in fact, many instances of idiopathic EM minor may be precipitated by subclinical HSV infection [3]. In cases caused by HSV, EM tends to occur 1 to 3 weeks after the onset of the HSV symptoms (post-herpetic EM) [10]. A study was conducted in Denver to assess the potential role of HSV infection in the pathogenesis of EM minor in children where EM skin lesions from 20 children, aged 1 to 16 years, were examined for the presence of HSV by using the polymerase chain reaction and concluded that HSV is a significant precipitating factor for EM minor in children, as it is in adults, and that clinicians should maintain a high index of suspicion of HSV even in the absence of a known history of herpes infection [11].

A herpetic etiology also accounts for $55 \%$ of cases of EM major [12] and is also the most common cause of recurrent EM whereas persistent EM is associated with viral infections, as well as inflammatory bowel disease and malignancies [4].

\section{Mycoplasma}

Among other infections, Mycoplasma species appear to be a common cause [3] in which Mycoplasma pneumoniae is an important and highly relevant cause of bullous erythema multiforme, isolated mucositis, and SJS in children [13].

\section{Drugs}

Adverse skin reactions to drugs are frequent, with rates of reaction to many commonly used drugs exceeding 1\% [14]. Erythema multiforme, especially EM major and SJS can occur after taking certain medications, although medications are a less likely cause than an infection [15]. Regarding medications, sulfa drugs are the most common triggers (30\%). A slow acetylator genotype is a risk factor for sulfonamide-induced SJS [3]. The second most 
commonly involved agents are the anticonvulsants, including barbiturates, carbamazepine, hydantoin, phenytoin, and valproic acid. Prophylactic anticonvulsants after surgery for a brain tumor combined with cranial irradiation may result in life-threatening SJS [3].

Table 2: Medications associated with erythema multiforme [17].

\begin{tabular}{|c|c|}
\hline Drug & Details \\
\hline Antibiotics & $\begin{array}{l}\text { Sulphonamides, penicillin, ampicillin, tetracyclines, amoxicillin, } \\
\text { cefotaxime, cefaclor, cephalexin, ciprofloxacin, erythromycin, } \\
\text { minocycline, trimethoprim-sulfamethoxazole, and vancomycin. }\end{array}$ \\
\hline Non-steroidal anti-inflammatory drugs (NSAIDs) & $\begin{array}{l}\text { Piroxicam, fenbufen, ibuprofen, ketoprofen, naproxen, tenoxicam, } \\
\text { diclofenac, sulindac, aspirin, phenylbutazone, oxyphenbutazone, and } \\
\text { phenazone. }\end{array}$ \\
\hline Anti-tuberculoid & Rifampicin, ethambutol, isoniazid, and pyrazinamide. \\
\hline Anticonvulsants & Barbiturates, carbamazepine, phenytoin, and valproate. \\
\hline Anti-fungals & Fluconazole, nystatin, and griseofulvin. \\
\hline Antidepressants & Lamotrigine and sertraline. \\
\hline Oral hypoglycaemic & Chlorpropamide and tolbutamide. \\
\hline Others & $\begin{array}{c}\text { Allopurinol, Acarbose, clofibrate, corticosteroids, hydralazine, } \\
\text { mefloquine, methotrexate, minoxidil, nifedipine, oestrogen, } \\
\text { progesterone, verapamil, thiouracil, albendazole, arsenic, bromofluorene, } \\
\text { quinine, cimetidine, didanosine, dideoxycytidine, etretinate, gabapentin, } \\
\text { granulocyte-macrophage colony-stimulating factor, indapamide, } \\
\text { indinavir, methazolamide, meprobamate, mercurials, nitrogen mustard, } \\
\text { phenolphthalein, potassium iodide, suramin, saquinavir, thiabendazole, } \\
\text { terbinafine, theophylline, verapamil, gold, and dihydrocodeine } \\
\text { phosphate. }\end{array}$ \\
\hline
\end{tabular}

\section{Pathogenesis}

Although the precise pathogenesis is unknown, there is a tendency to consider EM both minor and major as part of one spectrum that is most often triggered by viral infections, and SJS and TEN as a separate one most often elicited by drugs with EM major and SJS representing a bridge in the continuum of EM. Significant differences exist among EM minor, EM major, SJS, and TEN with regards to severity and clinical expression; however, all variants share two common features: typical or less typical cutaneous target lesions and satellite-cell or more widespread necrosis of the epithelium. These features are considered to be sequelae of a cytotoxic immunologic attack on keratinocytes expressing non-selfantigens. These antigens are primarily microbial (viruses) or drugs and in rare instances histocompatibility antigens [18].

From immune-pathological aspect, minor EM is caused by type III hypersensitivity reaction, which involves immune complex reaction of antigen and antibody. Biopsy on blood vessel wall of EM patient found the increasing level of immunoglobulin M, complement and fibrin deposits. The pathogenesis is divided into three steps: the formation of antigen-antibody complex in circulation, the deposit of immune complex in numerous tissues, and the appearance of inflammatory reaction in many parts of the body. On the first stage, when antigen enters the body, specific antibody will be produced. And then in the circulation system these two form antigen-antibody complex. If the antigen could not be eliminated or phagocyte cells fail to do its function, antigen will be in the circulation for a longer time.
However, a retrospective study done in the patients hospitalized in Taiwan between 1988 and 2004 revealed that medications were the most common cause of any condition of EM: for SJS, carbamazepine was most common; for EM or TEN, allopurinol was most common.16 Some of the medications that can trigger a reaction are mentioned in (Table 2) $[16,17]$.

Sulphonamides, penicillin, ampicillin, tetracyclines, amoxicillin cefotaxime, cefaclor, cephalexin, ciprofloxacin, erythromycin, diclofenac, sulindac, aspirin, phenylbutazone, oxyphenbutazone, and Rifampicin, ethambutol, isoniazid, and pyrazinamide. Barbiturates, carbamazepine, phenytoin, and valproate. Fluconazole, nystatin, and griseofulvin. Lamotrigine and sertraline.

Allopurinol, Acarbose, clofibrate, corticosteroids, hydralazine, mefloquine, methotrexate, minoxidil, nifedipine, oestrogen, progesterone, verapamil, thiouracil, albendazole, arsenic, bromofluorene, uinine, cimetidine, didanosine, dideoxycytidine, etretinate, gabapentin, granulocyte-macrophage colony-stimulating factor, indapamide, indinavir, methazolamide, meprobamate, mercurials, nitrogen mustard, terbinafine, theophylline, verapamil, gold, and dihydrocodeine

This situation can also be caused by malfunctioned macrophage, leading to deposition of immune complex in many parts and causing vasculitis. Immune complex which leave circulation and deposit inside or outside blood vessel wall, will cause the increase of blood vessel permeability. This condition is marked by immune complex which bound with inflammatory cells through Fc and C3b receptors and trigger the release of vasoactive and cytokine mediators. On condition when immune complex deposit within the tissues, third inflammatory reaction occurs. In this stage appear symptoms such as fever, urticaria, arthralgia, and lymphoid gland expansion. This can happen in the beginning of erythema multiforme to quickly appear its clinical manifestation, but the prodromal symptoms which precede it may not as severe as in diseases of viral infections [5].

The major type of EM is mostly caused by autoimmune process and from untreated minor type of EM. In histopathology examination, autoantibody on desmoplakins 1 and 2 are found, which show the involvement of humoral immune system. This can be used as a way to help the diagnosis of erythema multiforme, to be differentiated by its differential diagnosis [5].

The phenomenon of autoimmune is often connected with genetics. There are genetic components which are identical to Human Leukocyte Antigen (HLA) specificity, as in systemic lupus erythematosus with Class II HLA gene especially on HLA-DQ locus. In relation with microbes, some bacteria, microplasm, and virus are able to trigger the autoimmune reaction through several 
mechanisms, such as: epitop recognition which cross linked with host antigen, microbial antigen and auto antigen combined forming an immunogenic unit to activate the tolerance of $\mathrm{T}$ cell, some virus and bacteria as a mitogen to $\mathrm{T}$ cell or B cell non specific polyclonal which can induce the formation of antibody, and microbial infection with tissue necrosis and inflammation which can activate antigen presenting cell (APC) stimulation in tissues [5].

\section{Infections}

The association between EM and HSV infection has long been appreciated, although the exact role which HSV may play in the pathogenesis of this herpes-associated EM (HAEM) is unknown. The presence of HSV would support the hypothesis that an immunemediated response directed against HSV-specific antigens in the skin is central to lesion development in HAEM [19].

New data are presented which suggest that autoreactive T-cells triggered by virus infection play an important role in HAEM pathogenesis. Disease development begins with viral DNA fragmentation and the transport of the DNA fragments to distant skin sites by peripheral blood mononuclear cells (PBMCs). HSV genes within DNA fragments deposited on the skin [notably DNA polymerase (Pol)] are expressed, leading to recruitment of HSV-specific CD4+ Th1 cells that respond to viral antigens with production of interferon-gamma (IFN- $\gamma$ ). This step initiates an inflammatory cascade that includes expression of IFN- $\gamma$ induced genes, increased sequestration of circulating leukocytes, monocytes and natural killer (NK) cells, and the recruitment of autoreactive T-cells generated by molecular mimicry or the release of cellular antigens from lysed cells. The PBMCs that pick up the HSV DNA [viz. macrophages or CD34+ Langerhans cells (LC) precursors], their ability to process it, the viral proteins expressed in the skin and the presence of epitopes shared with cellular proteins may determine whether a specific HSV episode is followed by HAEM development [1] (Figure 1).

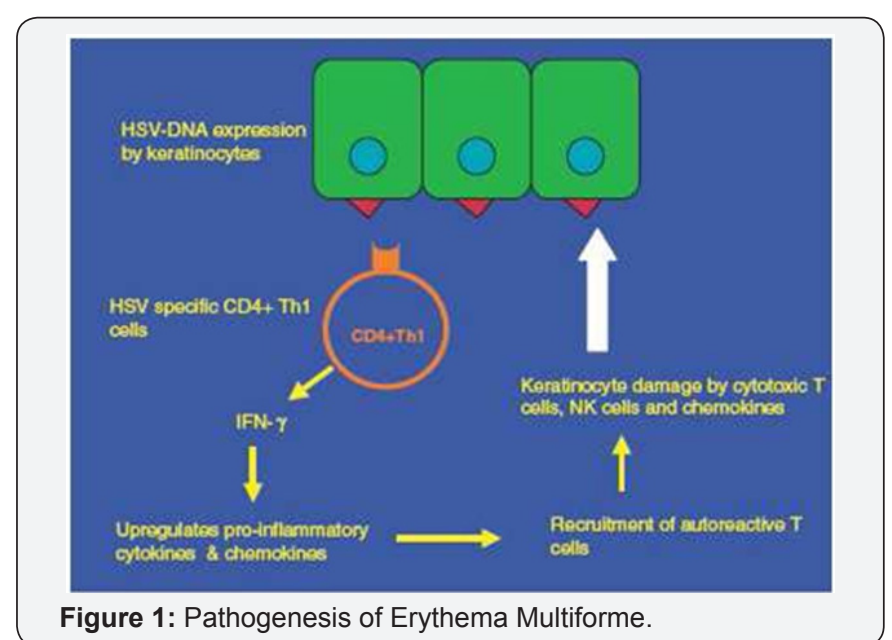

Figure 1: Pathogenesis of Erythema Multiforme.

Previous reports have shown an increased frequency of certain HLA antigens in association with EM, including HLAB15(B62), HLA-B35, HLA-A33, HLA-DR53 and, more recently, HLA-DQB1*0301. A strong association with HLA-DQ3 has been documented in patients with recurrent erythema multiforme. The HLA antigens A1, B8, and DR3 are associated with autoimmune disease, reflecting an increased host response to tissue self antigens. Their absence in patients with recurrent erythema multiforme may be an indicator of a poor host response to an antigen, which in the case of recurrent erythema multiforme is the HSV [20].

\section{Drug hypersensitivity}

Drug-associated EM (DIEM) is a mechanistically distinct EM subset that involves expression of tumor necrosis factor alpha (TNF- $\alpha$ ) in lesional skin 10 and not interferon- $\gamma$ as in HAEM lesions, suggesting a varying mechanism [21]. The disease process also often involves an abnormal metabolism of a responsible drug. As noted above, the keratinocyte is the ultimate target of this disease process, with keratinocyte necrosis being the earliest pathologic finding. Patients frequently display an altered metabolism of the responsible drug, and are considered to be slow acetylators, both genotypically and phenotypically. This means that an increased proportion of drug metabolism is directed toward the alternative pathway of oxidation by the cytochrome P-450 system, resulting in increased production of reactive and potentially toxic metabolites. Affected individuals have a defect in the ability to detoxify these reactive metabolites, which may then behave as haptens by binding covalently to proteins on the surface of epithelial cells. This may then induce the immune response, leading to the severe skin reaction [3]. Much of the tissue damage in drug-induced lesions appears to be due to apoptosis and, because of the paucity of the inflammatory reaction. However, particularly in TEN and SJS, there is some evidence for apoptosis-associated molecules Fas and Fas ligand (Fas-FasL) interaction. FasL mediates apoptotic cell death by binding to Fas on cells and inducing the formation of caspases. Fas is present on keratinocytes and FasL is found on activated T cells and NK cells and thus binding of keratinocytes to T cells or NK cells can induce apoptosis [22,23].

\section{Conclusion}

Through this literature review, it can be concluded that EM is classified into 2 types, the minor type that is associated with recurrent HSV and it is a hypersensitivity reaction by vasculitis on antigen antibody complex reaction, and the more serious syndrome, EM major, or SJS that is usually caused by autoimmune process to drugs and mycoplasmal infections.

Making the distinction between these conditions is valuable for providing adequate therapy and predicting the prognosis of this entity. Hence, progress in the understanding of EM will require careful attention to etiologic subsets and immunopathogenesis within the spectrum of EM.

\section{References}

1. Aurelian L, Ono F, Burnett J (2003) Herpes simplex virus (HSV)associated erythema multiforme (HAEM): a viral disease with an autoimmune component. Dermatol Online J 9(1): 1.

2. Khalil I, Lepage V, Douay C, Morin L, Wallach D, et al. (1991) HLA DQB1*0301 allele is involved in the susceptibility to erythema multiforme. J Invest Dermatol 97(4): 697-700. 
3. http://emedicine.medscape.com/article/1122915-overview.

4. Francesco D, Aurora P, Alfredo R (1995) Persistent erythema multiforme: Report of two new cases and review of literature. J Am Acad Dermatol 33(2): 366-369.

5. Maharani LA, Retno PR (2009) Immunopathological aspects of oral erythema multiforme. Dent J (Maj Ked Gigi) 42(4): 159-163.

6. Huff JC, Weston WL, Tonnesen MG (1983) Erythema multiforme: A critical review of characteristics, diagnostic criteria, and causes. J Am Acad Dermatol 8(6): 763-775.

7. Samim F, Auluck A, Zed C, Williams PM (2013) Erythema multiforme: A review of epidemiology, pathogenesis, clinical features, and treatment. Dent Clin North Am 57(4): 583-596.

8. Tennesson MG, Soter NA (1979) Erythema multiforme. J Am Acad Dermatol 1: 357-364.

9. Yetiv JZ, Bianchine JR, Owen JA (1980) Etiologic factors of the Stevens Johnson syndrome. South Med J 73(5): 599-602.

10. Margaret Lemak A, Madeleine Duvic, Samuel Bean F (1986) Oral acyclovir for the prevention of herpes-associated erythema multiforme. J Am Acad Dermatol 15(1): 50-54.

11. Weston WL, Brice SL, Jester JD, Lane AT, Stockert S, et al. (1992) Herpes simplex virus in childhood erythema multiforme. Pediatrics 89(1): 32 34.

12. Lamoreux MR, Sternbach MR, Hsu WT (2006) Erythema multiforme. Am Fam Physician 74(11): 1883-1888.

13. Schalock PC, Dinulos JG, Pace N, Schwarzenberger K, Wenger JK, et al. (2006) Erythema multiforme due to Mycoplasma pneumoniae infection in two children. Pediatr Dermatol 23(6): 546-555.

14. Isik SR, Karakaya G, Erkin G, Kalyoncu AF (2007) Multidrug-Induced Erythema Multiforme. J Investig Allergol Clin Immunol 17(3): 196-198.
15. Mockenhaupt M (2011) The current understanding of Stevens-Johnson syndrome and toxic epidermal necrolysis. Expert Review of Clinical Immunology 7(6): 803-813.

16. Chang YS, Huang FC, Tseng SH, Hsu CK, Ho CL, et al. (2007) Erythema multiforme, Stevens-Johnson syndrome, and toxic epidermal necrolysis: acute ocular manifestations, causes, and management. Cornea 26(2): 123-129.

17. Mockenhaupt M, Viboud C, Dunant A, Naldi L, Halevy S, et al. (2008) Stevens-Johnson syndrome and toxic epidermal necrolysis: Assessment of medication risks with emphasis on recently marketed drugs. The EuroSCAR-study. J Invest Dermatol 128(1): 35-44.

18.Ayangco L, Rogers RS 3rd (2003) Oral manifestations of erythema multiforme. Dermatol Clin 21(1): 195-205.

19. Brice SL, Krzemien D, Weston WL, Huff JC (1989) Detection of herpes simplex virus DNA in cutaneous lesions of erythema multiforme. J Invest Dermatol 93(1): 183-187.

20. Schofield JK, Tatnall FM, Brown J, McCloskey D, Navarrete C, et al (1994) Recurrent erythema multiforme: Tissue typing in a large series of patients. Br J Dermatol 131(4): 532-535.

21. Farthing P, Bagan JV, Scully C (2005) Mucosal disease series. Number IV. Erythema multiforme. Oral Dis 11(5): 261-267.

22. Iwai K, Miyawaki T, Takizawa T, Konno A, Otha K, et al. (1994) Differential expression of bcl-2 and susceptibility to anti-Fas-mediated cell death in peripheral blood lymphocytes, monocytes, and neutrophils. Blood 84(4): 1201-1208.

23. Sayama K, Yonehara S, Watanabe Y, Miki Y (1994) Expression of Fas antigen on keratinocytes in vivo and induction of apoptosis in cultured keratinocytes. J Invest Dermatol 103(3): 330-334.

\begin{tabular}{l} 
Your next submission with Juniper Publishers \\
will reach you the below assets \\
- Quality Editorial service \\
- Swift Peer Review \\
- Reprints availability \\
- E-prints Service \\
- Manuscript Podcast for convenient understanding \\
- Global attainment for your research \\
- Manuscript accessibility in different formats \\
( Pdf, E-pub, Full Text, Audio) \\
- Unceasing customer service \\
Track the below URL for one-step submission \\
https://juniperpublishers.com/online-submission.php \\
\hline
\end{tabular}

